\title{
Record management practices in labour organisations in Botswana
}

\author{
Authors: \\ Trywell Kalusopa ${ }^{1}$ \\ Patrick Ngulube ${ }^{2}$ \\ Affiliations: \\ ${ }^{1}$ Department of Library \\ and Information Studies, \\ University of Botswana, \\ Botswana \\ ${ }^{2}$ Department of \\ Interdisciplinary Research \\ of the College of Graduate \\ Studies, University of South \\ Africa, South Africa \\ Correspondence to: \\ Patrick Ngulube \\ Email: \\ ngulup@unisa.ac.za \\ Postal address: \\ PO Box 392, UNISA 0003, \\ South Africa \\ Dates: \\ Received: 13 Jan. 2012 \\ Accepted: 01 Apr. 2012 \\ Published: 29 June 2012 \\ How to cite this article: \\ Kalusopa, T. \& Ngulube, P., \\ 2012, 'Record management \\ practices in labour \\ organisations in Botswana', \\ SA Journal of Information \\ Management 14(1), Art. \\ \#513, 15 pages. http:// \\ dx.doi.org/10.4102/sajim. \\ v14i1.513
}

(C) 2012. The Authors. Licensee: AOSIS OpenJournals. This work is licensed under the Creative Commons Attribution License.
Background: This article is part of a doctoral research study that, amongst others, assessed e-records readiness and examined the current records management practices in labour organisations in Botswana.

Objective: The main objective of the study was to examine records management practices in labour organisations in Botswana

Methods: A quantitative paradigm largely guided this study. The researchers used a survey research strategy. Methodological triangulation of both quantitative and qualitative data collection methods complemented the strategy. The researchers surveyed all of the 50 registered labour organisations in Botswana. Of these, 45 responded. This is a response rate of $90 \%$. The researchers obtained their data through structured questionnaires, semi-structured interviews, document reviews and observations.

Results: The study showed that labour organisations in Botswana had some form of records management function. However, the management of both paper-based and electronic records was not satisfactory and fell short of the best-recognised records management standards and practices.

Conclusion: Although the researchers limited the study to labour organisations, it sheds light on the challenges of managing records that most organisations in Botswana face. Its results provide useful strategic recommendations to promote effective records management in labour organisations in Botswana and elsewhere in Africa.

\section{Introduction}

All organisations create records to support, and provide evidence of, their transactions. Consequently, records, regardless of their formats, are important sources of information and knowledge. They ensure effective transparency and accountability in decision-making and contribute to national development (International Records Management Trust [IRMT] 2003; Kemoni 2007). Therefore, sound management of records, whether electronic or paper, has become a topical issue globally.

The World Bank (2006) and the IRMT (2003) concur that records are essential for the effective and productive functioning of private and public organisations. They assert that records register the decisions and activities of governments and other organisations and serve as benchmarks against which they can measure their future activities and decisions. Without records, there can be no rule of law and no accountability (IRMT 2003; World Bank 2006). In addition, without good records, organisations make ad hoc decisions without the benefit of institutional memories.

Kalusopa (2011) observes that, for labour organisations to participate meaningfully in the national development process, they must develop the capacity to manage records and information. The reason is that the challenges of conceiving, initiating, implementing, monitoring and evaluating activities will always require reliable, pertinent and timely records as well as information (Kalusopa 2011).

Therefore, this article records empirical findings about the extent to which labour organisations in Botswana manage their records in the context of good records management practices.

\section{Contextual setting - labour organisations in Botswana}

Labour organisations, or trade unions, are member-based and comprise workers who have come together to achieve common goals in areas like wages, working hours and conditions (Rainsberger 1998:1). Many labour organisations exist to advance the cause of workers by engaging with social and economic orders. They could accept an order and, within it, achieve a 'favourable set of 
economic terms and employment conditions, or they may seek to overthrow the existing economic system and replace it with another' (Rainsberger 1998:1).

Labour organisations in Botswana are not very distinctive. However, one can divide them into two broad categories: public and private sector organisations.

Public sector labour organisations are largely those in the public service, local government and education sectors whilst the private ones are those that operate in the industrial and commercial sectors of the economy.

Available statistics show that there are 50 registered labour organisations in Botswana (Registrar of Trade Unions 2011). The main national labour federation is the Botswana Federation of Trade Unions (BFTU). It is a federation of 29 labour organisations, or affiliates, and represents about $58 \%$ of the legally registered trade unions in the country. The other $42 \%$ operate legally, but outside the structure of the BFTU (Kalusopa 2011). A splinter federation, the Botswana Federation of Public Service Unions (BOFEPUSU), formed recently. At the time of writing this article, this federation did not have legal registration.

A literature review showed that, from the early 1970s, labour organisations in Botswana tended to undergo structural, legislative and ideological transformations. The most recent and significant changes to labour legislation, in 2004, allowed freedom of association. It led to a proliferation of labour organisations in Botswana. It also led to labour organisations becoming actively involved in the national development process.

At the level of organisations, unions provide workers with a collective voice. At national level, they work with government and other stakeholders to provide harmonious labour relations. Therefore, one can say that labour organisations in Botswana are a cornerstone of socioeconomic development because they are part of a system of industrial relations and productivity that tries to balance the need for enterprises to remain competitive with the aspiration of workers for higher wages and better working conditions (Friedrich Ebert Stiftung [FES] 2008; Kalusopa 2011). Therefore, like elsewhere in the world, the roles of labour organisations in Botswana go far beyond workplace trade unionism (FES 2008). Labour organisations strive to ensure the transformation of development needs so that they no longer serve only the narrow interests of government or global capital and, instead, focus also on advancing the interests of workers and the people (Kanyenze, Kondo \& Martens 2006). Consequently, the role of labour organisations is to monitor and measure progress with inclusive participatory national economic processes and good corporate ethics that the principles of openness, integrity and accountability underpin (Kanyenze, Kondo \& Martens 2006).

However, as several studies have pointed out, for labour organisations to perform their role meaningfully in organisations and at national level in Botswana, they need to develop their capacity to manage records and information effectively (FES 2008; Kalusopa 2009; Kalusopa 2010; Kalusopa 2011).

\section{Methodology}

The main purpose of the study was to examine records management practices in labour organisations in Botswana. A quantitative paradigm largely guided the study. The researchers used a survey research strategy. Methodological triangulation of the quantitative and qualitative data collection methods complemented it.

The researchers surveyed the 50 registered labour organisations in Botswana. Of these, 45 responded. This is a response rate of $90 \%$. They obtained their data from structured questionnaires, semi-structured interviews, document reviews and observations. They analysed the quantitative data to produce a set of descriptive results and analysed the qualitative data for a set of thematic results. They compared the two sets of results to produce a single interpretation and drew conclusions.

\section{Findings and discussion}

In discussing the findings of the study, it is prudent to emphasise that records management theory and practice underline the need to develop a records and information framework or environment that complies with international records management standards. In particular, the ISO 15489 (International Standards Organisation, Records and Documentation - Records Management), referred to as ISO 15489-1 (2001), is a useful guide.

The International Standards Organisation used the Australian Standard AS 4390 as its basis to develop ISO 15489 (Information and Documentation-Records Management Part 1: General) in response to consensus amongst some ISO member countries to standardise international best practices in records management. It applies to records, irrespective of their formats or media, which public or private organisations create or receive during the course of their activities (ISO 2001a:4). The findings and discussions are its tenets of best records management.

The researchers present and discuss them under the themes that follow:

- legislative and regulatory framework

- creating and capturing records

- uses of records

- formats of records

- organising and classifying record collections

- accessing and retrieving records

- appraising, retaining and disposing of records

- storing and preserving records

- staffing and training

- managing vital records and disasters

- managing mail

- managing emails

- managing e-records. 


\section{Legislative and regulatory framework}

Record management best practice means that organisations should provide adequate evidence of their compliance with the regulatory environment in the record of their activities. These are usually statutes, mandatory standard practices, codes of best practice and codes of conduct and ethics. The nature of the organisations and sectors determine the regulatory elements (ISO 15489-1: Section 5).

The survey revealed that there was some guidance about the requirements for managing records in the relevant acts, instructions and instruments. However, there was no detailed guidance, which labour organisations need to manage their records, about relevant policies and practices.

It confirms the findings of several studies that reveal the challenges that relate to effective legislative and regulatory frameworks for managing records, regardless of their formats, in countries in the East and Southern Africa Regional Branch of the International Council on Archives (ESARBICA) (IRMT 2008; Keakopa 2006; Nengomasha 2009).

The findings also show that the Botswana National Archives and Records Services (BNARS) Act of 1978 was amended in 2007 in order to strengthen work on current or active records, including electronic records. However, further analysis shows that the BNARS act has a strong emphasis on managing records in the public service. In effect, BNARS has undertaken to play an advisory role to government on managing records and does not extend this to other organisations, like labour organisations. BNARS confirmed in interviews that their major problem was insufficient professionally skilled personnel (Kalusopa 2011).

\section{Creating and capturing records}

Scholars of records management theory and practice agree that, in principle, organisations should create and capture records for every activity that involves more than one party and that they should identify and record every process that generates records (Bearman 1994:300; Reed 1997:222; Shepherd \& Yeo 2003:102).

Therefore, records must be authentic, complete and usable. For example, even information communication technology (ICT) systems must be able to generate or capture the 'metadata' that record the contents, contexts and structures of records within the business processes that produce them (IRMT 2008:30). According to Shepherd and Yeo (2003:102), when assessing the need to create and capture records, it is essential to consider:

- the requirements of the organisations or particular business units that need records to provide evidence and information for operational use

- the requirements of the organisations, particular business units or external stakeholders that need evidence to ensure accountability

- the cost of creating, capturing and maintaining the records that organisations require and the risk to them if they do not have these records.

A policy for creating records is also necessary. It should stipulate the requirements for capturing, registering, classifying, retaining, storing, tracking, accessing and disposing of records (ISO 15489-1 2001:7).

Therefore, the survey sought to ascertain the types of records labour organisations create, which functions create the most records, and if they had recordkeeping systems.

The researchers asked labour organisations to state the extent to which each main activity created records. They used a Likert scale to measure the levels of agreement or disagreement about which activity generated records. Most of them $(38$, or $84 \%)$ cited internal and external communication. Other responses follow:

- $37(82 \%)$ agreed that it was union administration

- $34(75.6 \%)$ agreed that it was services to members

- $34(75.6 \%)$ agreed that it was collective bargaining

- $32(71.1 \%)$ agreed that organising and mobilisation produced most records

- $30(66.7 \%)$ agreed that it was education and training activities

- $27(60 \%)$ agreed that it was sending solidarity information

- $27(60 \%)$ agreed that it was correspondence to, and discussions with, international trade union bodies (see Table 1).

Observations and interviews revealed that most of the labour organisations had some forms of recordkeeping systems that administrative staff, mostly receptionists and secretaries who had some office practice qualifications or experience, usually managed.

Interviews and observations also revealed that some limited administrative procedures or instructions guided the creation of records. They included conventions or codes

TABLE 1: Activities that produce records in labour organisations $(N=45)$.

\begin{tabular}{|c|c|c|c|c|c|c|c|}
\hline Activities that produce records & Strongly agree & Agree & Neutral & Disagree & Strongly disagree & No response & Total \\
\hline Collective bargaining & $16(35.6 \%)$ & $18(40 \%)$ & $3(6.7 \%)$ & $1(2.2 \%)$ & - & $7(15.6 \%)$ & $45(100 \%)$ \\
\hline Organising & $15(33.3 \%)$ & $17(37.8 \%)$ & $5(11.1 \%)$ & $3(6.7 \%)$ & - & $5(11.1 \%)$ & $45(100 \%)$ \\
\hline Internal and external communication & $15(33.3 \%)$ & $23(51.1 \%)$ & $2(4.4 \%)$ & - & - & $5(11.1 \%)$ & $45(100 \%)$ \\
\hline Services to members & $12(26.7 \%)$ & $22(48.9 \%)$ & $6(13.3 \%)$ & $1(2.2 \%)$ & - & $4(8.9 \%)$ & $45(100 \%)$ \\
\hline Education and training & $13(28.9 \%)$ & $17(37.8 \%)$ & $9(20 \%)$ & $3(6.7 \%)$ & - & $3(6.7 \%)$ & $45(100 \%)$ \\
\hline Sending solidarity information & $7(15.6 \%)$ & $20(44.4 \%)$ & $8(17.8 \%)$ & $2(4.4 \%)$ & - & $8(17.8 \%)$ & $45(100 \%)$ \\
\hline Union administration & $18(40 \%)$ & $19(42.2 \%)$ & $2(4.4 \%)$ & $1(2.2 \%)$ & - & $5(11.1 \%)$ & $45(100 \%)$ \\
\hline
\end{tabular}


about creating records like letters, memos and reports. The codes contained titles, greetings and reference numbers that organisations should use. However, there were no welldefined or clear procedures or policies to guide the creation of records in most of the labour organisations.

The absence of record creation guidelines and policies is not new in the ESARBICA region. Kemoni (2007) focused on records management for public service delivery in Kenya. Kemoni (2007:290) found that 88 (56\%) records management units did not have a policy for creating records, whilst 107 $(68 \%)$ admitted they 'did not have a list of activities which constituted the basis for record creation'. Kemoni (2007:291) bemoaned the negative effects of not creating 'authentic, reliable, complete, unaltered' records. The situation in labour organisations will probably be similar. Therefore, the absence of a creation policy could have severe implications for labour organisations. Most of these trade unions handle members' cases, disputes, financial obligations within and outside the organisations that require evidence. It would be in their interest to ensure that there is confidence about the authenticity of the records they create or capture for current and future use.

\section{Uses of records}

Organisations create and keep records so that designated users, mostly from within the organisations and occasionally from outside them, can use them when they need to. Any records management system that captures records must have systems that allow users to use the records systematically (Shepherd \& Yeo 2003:216). Therefore, organisations create records for a purpose.

The study revealed that most labour organisations keep records that assist them in their work. The researchers asked respondents to state, using a multi-response list, the main users of most of these records. The study revealed that the executive leaders (41, or $37.3 \%)$, followed by union staff $(28$, or $25.5 \%$ ), used the records most. See Table 2.

It was surprising to note that only $21(19.1 \%)$ organisations indicated that the general members were the main users of the records, given that labour organisations are supposed to be member-driven. The implication is that, despite the claims that shared beliefs, which members drive, underline trade union values, the evidence suggests that the organisational culture of labour organisations reflects a mixture of 'power' and 'role' where there is centralised power around a few people that some level of bureaucrats identified.

The interviews revealed two salient points that one can attribute to this state of affairs. One is that most of members were not actively engaged in seeking information but relied on leaders for it. The other is the effect of the organisational culture on records management.

One can define organisational culture as the values, attitudes, beliefs and behaviours that characterise the working environments, objectives and visions of organisations (Hofstede 1980:1). Shepherd and Yeo (2003:45) posit that organisational culture affects the different approaches or strategies to managing records. Using Handy's (1993) conceptualisation, Shepherd and Yeo (2003:45) present organisational cultures as power (with a strong sense of power at the centre), role (built on bureaucracy), task or achievement (focused on projects or outcomes) and cluster or support (without a definite structure and a tendency to be fluid).

Shepherd and Yeo (2003) argue that a role culture relies on regulation whilst a power culture relies on the day-to-day supervision of lower levels by the powerful. In this regard, they argue that managing records thrives on regulation 'and is best suited to organisations with role culture'. They argue further that the issue of external and internal accountability is central to a role and power culture and that:

record management based on the need for external accountability may be marketable in role culture rather than power culture... [while] internal accountability is an important issue in both role and power culture. (p. 45)

Although Shepherd and Yeo (2003:42) assert that trade unions have power cultures, a close analysis of the organisational culture of most labour organisations in the present study showed that most of them had a mixture of power and role cultures.

Therefore, most labour organisations in Botswana have centralised power around a few 'elected' people with semblances of formal bureaucratic organisational structures. A power culture tends to control information from the centre - the elected executive at the expense of the general members.

Perhaps other findings in the study will confirm this. It used a multi-response list that indicated that the labour organisations actually used most of the records for administration (41 responses, or $20.3 \%$ of the responses) and trade union finance (40 responses, or 19.8\%) rather than for collective bargaining (32 responses, or 15.8\%) or organisation and recruitment (34 responses, or 16.8\%) that would actively involve members. See Table 3.

\section{Formats of records}

In addition to recording the policies and procedures for creating records in labour organisations, it is equally important for ISO-compliant records management programmes to record the types and formats of records that organisations create and maintain.

The format is particularly critical in the electronic environment, where the lifespan of a particular format limits its accessibility. The survey revealed that the paper format still dominated most of the records. Based on a multi-response list, the labour organisations indicated that the types of paper format were largely lever arch files (36 responses, or 20\%) and loose papers in folders (30 responses, or 17\%). See Figure 1.

Figure 2 shows that semi-structured (emails), with 29 responses (21\%), unstructured (the Microsoft software package - Word, Excel and PowerPoint), with 28 responses (20\%) and structured (databases), with 14 responses (10\%) 
TABLE 2: Users of records in labour organisations $(N=45)$.

\begin{tabular}{lcc}
\hline Users & \multicolumn{2}{c}{ Frequency } \\
\cline { 2 - 3 } & Total & $\mathbf{\%}$ \\
\hline Union staff & 28 & 25.5 \\
Executive leaders & 41 & 37.3 \\
Members & 21 & 19.1 \\
Not very sure & 20 & 18.2 \\
\hline Total & $\mathbf{1 1 0}$ & $\mathbf{1 0 0}$ \\
\hline
\end{tabular}

TABLE 3: Purposes for which labour organisations use records $(N=45)$.

\begin{tabular}{lcc}
\hline Purposes & \multicolumn{2}{c}{ Frequency } \\
\cline { 2 - 3 } & Total & $\mathbf{\%}$ \\
\hline Non-trade union matters & 1 & 0.5 \\
Trade union personnel & 25 & 12.4 \\
Trade union policy & 29 & 14.4 \\
Collective bargaining & 32 & 15.8 \\
Organising and recruitment & 34 & 16.8 \\
Trade union finance & 40 & 19.8 \\
Trade union administration & 41 & 20.3 \\
\hline Total & $\mathbf{2 0 2}$ & $\mathbf{1 0 0}$ \\
\hline
\end{tabular}

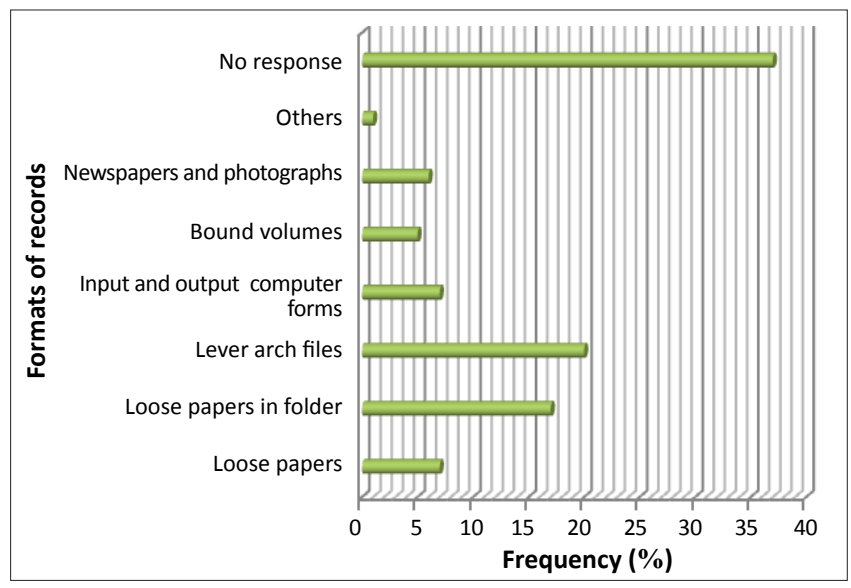

Source: Authors' own data

FIGURE 1: Format of records in labour organisations (paper).

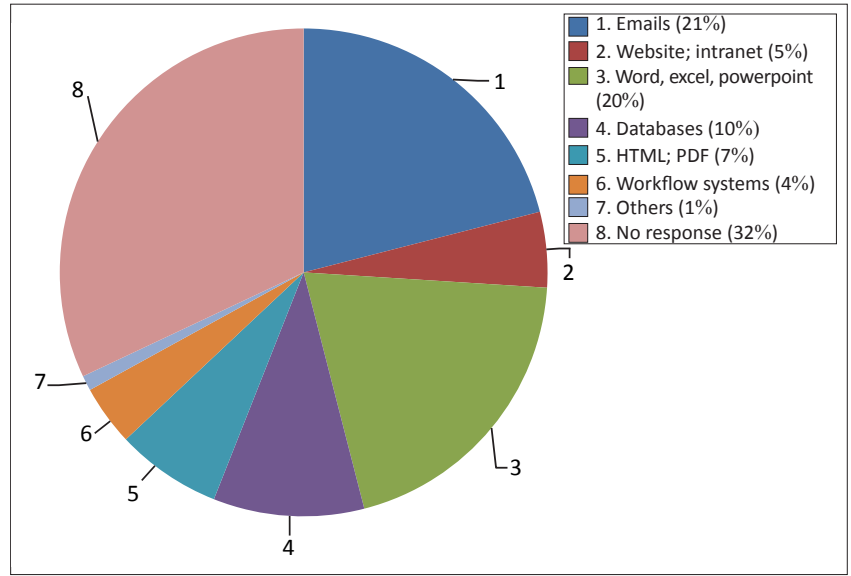

Source: Authors' own data

FIGURE 2: Format of records in labour organisations (electronic).

were the most common electronic formats for records in most labour organisations.

The dominance of paper and unstructured e-records (basic word processing) is similar to the findings of Moloi (2006:58) and Keakopa (2006:218) for the public sector in Botswana. Keakopa (2006:218) confirmed that, in all government agencies, there were records in both paper and electronic formats with 'the bulk of the records usually in paper format'. Keakopa (2006:218) states that although 'paper [was] a common medium of transmission and storage of information, electronic records [were] slowly becoming more common'.

Furthermore, the current study established, through interviews, that information about current record types and formats in most labour organisations was largely incomplete. This was because there were no systematic records surveys or inventories to capture the many records the organisations had created.

A records survey captures information about the records organisations hold, amongst others. Records surveys help to 'identify what records exist, which records need to be captured into recordkeeping systems, how long they need to be kept and where they should be located' (Northern Territory National Archives Services 2006:2). The information:

must be gathered on existing records to assess how adequately the recordkeeping requirements of the organisation are being met and whether improvements are required particularly when developing systems and controls for capturing and maintaining' records. (p. 2)

A records inventory is usually a product of a records survey and can be useful for:

planning a range of records management activities including disposal scheduling and procedures, secondary storage services, vital records protection, and rationalisation of the storage and management of active records future records. (Northern Territory Archives Services 2006:2)

Other researchers have focused on the issues of records surveys in the context of appraisal, retention and disposal. However, they have also emphasised the need for regular records surveys (Kemoni 2007:317; Ramokate \& Moatlhodi 2010:80). Labour organisations could also note and follow this advice.

\section{Organising and classifying record collections}

The timely and accurate retrieval of records depends largely on how well organised and classified the records are. Therefore, records classification systems should reflect the business activities of organisations. Organisations need to determine the degree of classification control they require for their business purposes (ISO 15489-1: Section 9.5).

Shepherd and Yeo (2003) also pointed out that:

classification schemes are based on an analysis of functions processes and activities... [and] document the structure of a records management system and the relationship between records and the activities that generate them. (p. 73)

Other researchers and authorities emphasise that any effective records management programme requires classification (Kemoni 2007; Reed 2005). Vocabulary control tools usually support classification systems. They give organisationspecific definitions and explain the usage of terms. 
The interviews and observations revealed that most labour organisations were not aware of the procedures for filing paper and electronic records, although most had developed some form of classification. Therefore, in the absence of well-defined, organisation-wide classification structures, most of the localised systems in labour organisations rely on the initiative and memory of union staff members, like secretaries and administrative staff, about how to classify records. Furthermore, when the researchers asked them to state how they organised their records, 16 (18.8\%) indicated that they classified their records alphabetically and another $16(18.8 \%)$ that they did so chronologically (Figure 3).

The researchers also observed that, because of the shortcomings that arise from not having file plans, most labour organisations had designed a number of homegrown record classification systems for hard copy and electronic records. They could improve efficiency for some labour organisations in the short term. However, in the long term, creating ad hoc and non-standard systems could undermine the objectives of integrating and sharing information resources.

Although they focused on the public sector, the earlier studies of Kemoni (2007) in Kenya and Nengomasha (2009) in Namibia also revealed the lack of updated classification systems. For example, Nengomasha (2009:212) found that two of the eleven institutions (18\%) did not have classification systems. However, even when they did have classification systems, most were outdated or not in use. Kemoni (2007:296) also found that, despite the claim of written classifications, observations showed the contrary. The study revealed that 'in the majority of the ministries, the classification schemes available were handwritten and some were in a state of deterioration, that is, they were faded, worn out and torn'.

The situation seems to be the same in the public sector in Botswana. Ramokate and Moatlhodi (2010:74) conducted a micro-appraisal of public records. It showed that most records in state departments were 'chaotic and un-co-ordinated' and 'among the other problems... [there was]...poor classification of records, as records were created and captured haphazardly without being informed by analysis of business process or functions'. In another study at the Gaborone City Council (GCC), Tshotlo and Mnjama (2010:23) revealed that, although it maintained a register or index in the Records Management Unit, in terms of 'physical arrangement, 8 (66.6\%) indicated their records [were] not arranged in any logical manner' and that they were 'in the process of developing a comprehensive file classification system'.

Therefore, it is clear that the problems of organisation and classification the labour organisations face still prevail in the central and local governments of Botswana. Nevertheless, these organisations boast about a professional and technical records management cadre from the BNARS.

\section{Accessing and retrieving records}

Effective retrieval systems that reflect the different levels of aggregation and formats are necessary. In paper systems, access is to a specific item in the file (or to the whole file). In the electronic environment, users require metadata at all levels (Shepherd \& Yeo 2003:217). Electronic records systems should include and apply controls for access to ensure that the integrity of records remains uncompromised. They should provide and maintain audit trails or other methods to show that they protect records effectively from unauthorised use, alteration or destruction (ISO 15489-1 2001: Section 8.3.6).

ISO 15489 also requires that organisations record the movement of records to ensure that users can locate the records whenever they need them. Tracking mechanisms can record the item identifier, the title, the person or unit that has an item and the time or date of the movement. The system should track the issue, transfer between persons and the return of records to their 'home' location or storage, as well as their disposal or transfer to any other authorised external organisation, including an archives authority (ISO 15489-1 2001: Section 9.8.3).

This study revealed that, when it comes to retrieving paper records, 24 (53.3\%) of the labour organisations indicated that they took minutes to retrieve information when they needed it, whilst $14(31.1 \%)$ of them indicated that they took hours to locate information (see Table 4).

This situation was the same in the electronic environment.

With regard to access, 23 of the labour organisations (21.7\%) indicated that the main problem they encountered was the shortage of staff trained to manage records. Another notable problem was the lack of, or poor, layout of records management (RMU) units (17.9\%), as Table 5 shows.

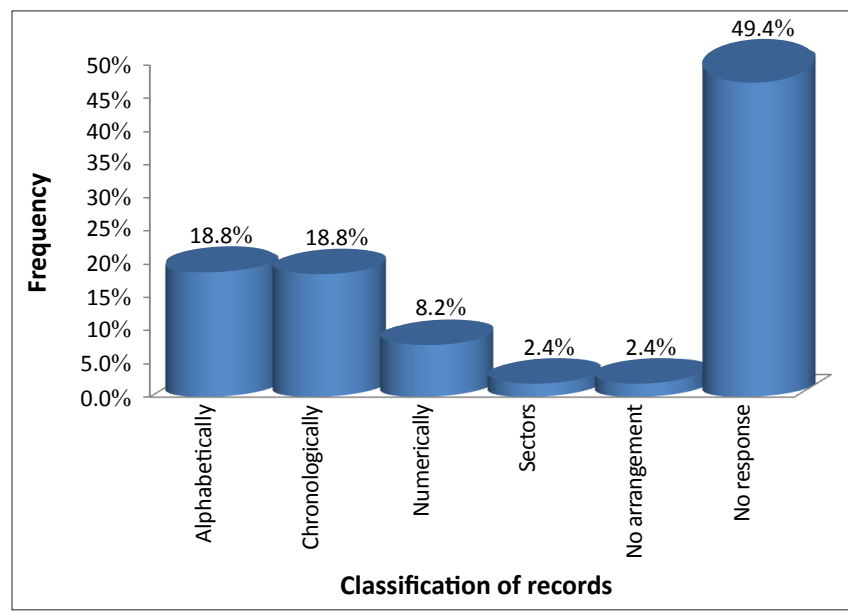

Source: Authors' own data

FIGURE 3: Classification of records in labour organisations.

TABLE 4: Length of time required to retrieve information in a paper-based environment $(N=45)$.

\begin{tabular}{lcc}
\hline Length of time & \multicolumn{2}{c}{ Frequency } \\
\cline { 2 - 3 } & Total & $\%$ \\
\hline Minutes & 24 & 53.3 \\
Hours & 14 & 31.1 \\
Days & 1 & 2.2 \\
Weeks & 1 & 2.2 \\
Months & 1 & 2.2 \\
Never located in some cases & 2 & 4.4 \\
No response & 2 & 4.4 \\
\hline Total & $\mathbf{4 5}$ & $\mathbf{1 0 0}$ \\
\hline
\end{tabular}


When the researchers asked the labour organisations to state whether there were any systems for tracking paper records, $24(53.3 \%)$ indicated that they did not have any tracking systems whilst $21(46.7 \%)$ indicated that they had. In general, $31(68.9 \%)$ of the labour organisations said they did not have detailed procedures for tracking records, regardless of their format, whilst 13 (28.9\%) indicated that they had.

The interviews and observations established that there were no file movement cards, for example. Therefore, when the researchers asked the labour organisations to state, using a multi-response list, the tools they used to track manual records, $26(39.4 \%)$ said they checked files on shelves physically to track the use of records. Only seven (10.6\%) used file tracking cards, five $(7.6 \%)$ used subject indexes and four $(6 \%)$ used computerised systems (see Table 6).

In a study in the public sector in Kenya, Kemoni (2007:179) also found that, for paper records, 127 (80.9\%) respondents indicated that they did not have procedures for tracking files. However, 120 (76.4\%) respondents indicated that file tracking registers were tools that they used widely to track records, whilst the remaining $37(23.6 \%)$ indicated that they used file-tracking registers and checked files physically.

The trend was similar in Botswana. Tshotlo and Mnjama (2010:24) confirmed that, although six (50\%) of the respondents at the GCC cited movement as a method they used to track their physical files, officers did not monitor the movement from one office to another. With regard to labour organisations, Tshotlo and Mnjama (2010:24) confirmed the poor record management practice of using human memory for tracking files. Three (25\%) respondents indicated this. They indicated that the retrieval time ranged from 'a few minutes to sometimes' at the GCC.

TABLE 5: Problems that labour organisations face when providing access to records $(N=45)$.

\begin{tabular}{lcc}
\hline Problems faced & \multicolumn{2}{c}{ Frequency } \\
\cline { 2 - 3 } & Total & $\%$ \\
\hline Staff do not understand user needs & 6 & 5.7 \\
Files torn and dusty & 7 & 6.6 \\
Files bulky & 10 & 9.4 \\
Action officers retaining files & 12 & 11.3 \\
Users know little about the records the & 13 & 12.3 \\
trade union holds & 16 & 15.1 \\
Active and inactive files mixed up & 19 & 17.9 \\
Lack of or poor RMU layout & 23 & 21.7 \\
Staff lack training in managing records & $\mathbf{1 0 6}$ & $\mathbf{1 0 0}$ \\
\hline Total & &
\end{tabular}

TABLE 6: Tools labour organisations use to track the use of records $(N=45)$

\begin{tabular}{lcc}
\hline Tools & \multicolumn{2}{c}{ Frequency } \\
\cline { 2 - 3 } & Total & $\%$ \\
\hline Computerised system & 4 & 6 \\
Subject index & 5 & 7.6 \\
File tracking card & 7 & 10.6 \\
Human memory & 9 & 13.6 \\
File-tracking register & 15 & 22.7 \\
Physical checking of files on shelves & 26 & 39.4 \\
\hline Total & $\mathbf{6 6}$ & $\mathbf{1 0 0}$ \\
\hline
\end{tabular}

\section{Appraising, retaining and disposing of records}

Organisations cannot retain files, irrespective of their format (paper or digital), indefinitely. The reason for this is the cost of storage and maintenance as well as slower and difficult access because of the high volumes.

Records management does, in theory and in practice, emphasise that it is necessary to use appraisal techniques to support decisions about retention, that is 'which records can be destroyed at an early stage, and which merit longerterm or indefinite retention' (Shepherd \& Yeo 2003:217). In terms of Section 8.3 of ISO 15489-1, records systems should be able to facilitate and implement decisions about retaining or disposing of records.

Therefore, the effective management of records requires that there are procedures for the timely disposal of records that organisations no longer need to support current business or those that they do not need to retain for legacy purposes.

Consequently, the survey tried to establish whether labour organisations have developed tools and procedures for disposing of its records. Surprisingly, most labour organisations (35, or $77.8 \%$ of the 45$)$ indicated that they had some form of retention and disposal programme whilst 10 (22.2\%) indicated that they did not.

However, follow-up interviews showed that most labour organisations did not have a clear grasp of what such a programme entailed. In general, there was considerable confusion about retention requirements and the need to retain records for accountability purposes. Some respondents thought that 'indefinite' retention was necessary whilst others felt that they could dispose of records as soon as they had served their immediate purposes.

The reality was that, whilst legislation should provide for some basic retention requirement for financial records, for example, there were no clear policies or procedures for retaining or disposing of records in most labour organisations. In some respects, most labour organisations had no retention schedules, but relied on standing instructions (like financial regulations for keeping records for seven years) or standard trade union administrative instructions.

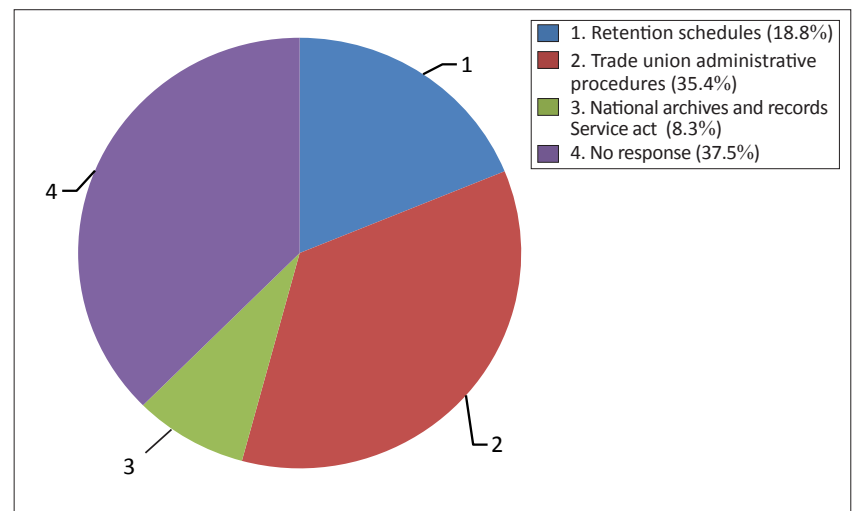

Source: Authors' own data

FIGURE 4: Instruments that guide disposal in labour organisations. 
Figure 4 shows that $17(35 \%)$ indicated that trade union administrative procedures were common instruments that guided records disposal in most labour organisations. The National Archives and Record Services Act was the least used instrument in labour organisations - only four (8.3\%) used this instrument.

This survey also showed that, just as with paper records, currently there are no clear rules and procedures that authorise the retention and disposal of the data the ICT systems hold. The implication of this is that the creators and users of records are able to capture, manipulate and delete data at their own discretion without any regard for the evidential value of the records.

In addition, of the 45 labour organisations, $28(62.2 \%)$ did not destroy records that they had not appraised, 15 (33.3\%) indicated they did destroy records after appraising them and two $(4.5 \%)$ did not respond. As a result, most of the labour organisations were clogging their recordkeeping systems.

Table 7 shows that most of the labour organisations tended to keep records permanently because they had no retention schedules. Therefore, it seems that most labour organisations require technical records management knowledge to deal with this problem and find an appropriate method to assess.

The IRMT (2003:5) showed that, amongst other challenges, there were no records retention and disposal policies in the ESARBICA region. Another study by Ngulube and Tafor (2006:62) confirmed this trend in Kenya, Namibia, South Africa, Tanzania and Zimbabwe. Other studies that Mutiti (2001), Ngulube (2004), Wato (2006), Wamukoya and Mutula (2005) conducted in the ESARBICA, that Kemoni (2007:317) conducted in Kenya and that Nengomasha (2009) conducted in Namibia, all confirm the absence of records retention and disposal policies.

In Botswana, Moloi (2006:58), Ramokate and Moatlhodi (2010:75) as well as Tshotlo and Mnjama (2010:23) confirm this. For example, Ramokate and Moatlhodi (2010:75) argued that policies for retaining and disposing of records in the public sector were non-existent, most of them 'date back to 1981' and were outdated. Tshotlo and Mnjama (2010:26) also note that, although some records at the GCC had moved to BNARS, 'it was not clear how the officers reached the decision to transfer the records', given that there were no retention and disposal schedules. This suggests that labour organisations in Botswana were in the same position as public sector organisations were and faced similar challenges.

However, Ramokate and Moatlhodi (2010:81) were optimistic about the public sector. They believed that, with the on-going computerisation of the BNARS project, called the National Archives and Records Management System (NARMS), records retention and disposal would be part of the automated system. They envisaged that the system would have 'mandatory functions' that would 'apply retention periods for records and provide a trigger for their implementation'. It would be the responsibility of the departments concerned to 'review and approve disposal action on the highlighted records'.

\section{Storing and preserving records}

Storage is essential for managing records because it ensures that records are secure, intact and accessible for as long as users need them (Shepherd \& Yeo 2003:173). Storage refers to physical space and to using dependable media. Section 9.6 of ISO 15489-1 (2001) states that records require storage conditions and handling processes that take into account their physical and chemical properties. Records, irrespective of their formats, require high quality storage and handling. Organisations should also store records in media that ensure their usability, reliability, authenticity and preservation for as long as users need them.

The survey revealed that each trade union centralised its storage of records at its secretariat whilst some officials kept records in their offices. There were no well-resourced and fully-fledged records management units, but many had some form of functional recordkeeping system.

Table 8 shows that $28(36.4 \%)$ of the labour organisations used steel cabinets for storing current records whilst 20 (26\%) used cupboards. The rest used adjustable shelves (11.7\%), wooden racks $(11.7 \%)$, non-adjustable shelves $(10.4 \%)$ and the floor (3.9\%).

In addition, with regard to the adequacy of the equipment the labour organisations used, $32(71.1 \%)$ of the 45 reported that they used equipment that did not sufficiently cater for records storage whilst only $13(28.9 \%)$ indicated that it was sufficient.

Some of these findings concur with those of Kemoni (2007:309), who found that the most common storage equipment in the

TABLE 7: Retaining records in labour organisations $(N=45)$.

\begin{tabular}{|c|c|c|c|c|c|c|c|c|}
\hline \multirow[t]{2}{*}{ Type of trade union records } & \multicolumn{8}{|c|}{ Retention periods of records in labour organisations } \\
\hline & $0-5$ years & $6-10$ years & $11-15$ years & $16-20$ years & $20-25$ years & $\begin{array}{l}\text { Permanent } \\
\text { preservation }\end{array}$ & No response & Total \\
\hline Financial & $10(22.2 \%)$ & $4(8.9 \%)$ & - & - & $1(2.2 \%)$ & $27(6 \%)$ & $3(6.7 \%)$ & $45(100 \%)$ \\
\hline General administration & $3(6.7 \%)$ & $4(8.9 \%)$ & $1(2.2 \%)$ & $1(2.2 \%)$ & $2(4.4 \%)$ & $32(71.1 \%)$ & $2(4.4 \%)$ & $45(100 \%)$ \\
\hline Union policy & $3(6.7 \%)$ & $2(4.4 \%)$ & $1(2.2 \%)$ & $1(2.2 \%)$ & - & $34(75.6 \%)$ & $4(8.9 \%)$ & $45(100 \%)$ \\
\hline Membership & $3(6.7 \%)$ & $4(8.9 \%)$ & - & $1(2.2 \%)$ & $2(4.4 \%)$ & $32(71.1 \%)$ & $3(6.7 \%)$ & $45(100 \%)$ \\
\hline Collective bargaining & $4(8.9 \%)$ & $4(8.9 \%)$ & - & - & $4(8.9 \%)$ & $27(6 \%)$ & $6(13.3 \%)$ & $45(100 \%)$ \\
\hline
\end{tabular}


public sector in Kenya was steel cabinets and that there were problems with the inadequacy of storage equipment. Other studies, like those of Wamukoya and Mutula (2005:75) in the ESARBICA and Nengomasha (2009:209) in Namibia, confirm the pattern.

In addition, 18 (16.7\%) labour organisations also indicated that they encountered problems of lost files and torn and dusty records whilst $17(15.7 \%)$ faced the problem of unauthorised access (see Table 9).

Nengomasha (2009:167) also found that $78 \%$ of the respondents in the public sector in Namibia had experienced a case, or cases, of lost records because of misfiling by registry staff, wrong reference numbers that action officers used and sending mail directly to action officers. In the public sector in Botswana, Moloi (2006:58) revealed that most respondents indicated that they encountered recordkeeping problems, amongst them being 'lost or missing files'.

With regard to the preservation strategies and practices for paper-based and digital resources, the study revealed that most labour organisations faced major problems. They include poor storage of electronic versions of documents or records, poor strategies for moving to newer hardware and software technologies, poor management of access control and using defective storage media.

The problems of digital preservation are also not new in Botswana. Kalusopa and Zulu (2009) surveyed 35 public and private institutions that they identified as having the actual ability or potential to manage digital materials in the country. These included institutions that operated in library services, archives and records management, museums, geological surveys, health, legal, education, research, revenue collection authorities, the financial services sector and media organisations (radio, television and newspapers). The study also revealed, amongst others:

TABLE 8: Storage of current records in labour organisations $(N=45)$.

\begin{tabular}{lcc}
\hline Place of storage & \multicolumn{2}{c}{ Frequency } \\
\cline { 2 - 3 } & Total & $\%$ \\
\hline Floor & 3 & 3.9 \\
Non-adjustable shelves & 8 & 10.4 \\
Wooden racks & 9 & 11.7 \\
Adjustable shelves & 9 & 11.7 \\
Cupboards & 20 & 26.0 \\
Steel cabinets & 28 & 36.4 \\
\hline Total & $\mathbf{7 7}$ & $\mathbf{1 0 0}$ \\
\hline
\end{tabular}

TABLE 9: Problems labour organisations face when storing records $(N=45)$.

\begin{tabular}{lcc}
\hline Problems faced & \multicolumn{2}{c}{ Frequency } \\
\cline { 2 - 3 } & Total & $\mathbf{\%}$ \\
\hline Lost file folios & 8 & 7.4 \\
Torn file covers & 13 & 12.0 \\
Unauthorised access & 17 & 15.7 \\
Torn and dusty files & 18 & 16.7 \\
Lost files & 18 & 16.7 \\
No response & 34 & 31.5 \\
\hline Total & $\mathbf{1 0 8}$ & $\mathbf{1 0 0}$ \\
\hline
\end{tabular}

- the absence of coordinated national initiatives and programmes on digitisation

- gaps in the necessary human resource requirements in terms of knowledge, skills and abilities to drive digital preservation

- the absence of standards for digital material preservation in terms of hardware, software, media and metadata storage.

\section{Staffing and training}

According to international records management practice (ISO 15489-1 2001: Section 11), organisations should establish ongoing programmes for training in managing records. Organisations can design or set up this training together with external bodies.

The survey established that most of the people who manage records and information in most labour organisations (35, or $77.8 \%$ ) had not received any education and training in managing records and only $10(22.2 \%)$ indicated that they had. The multi-response list showed that 10 (22.2\%) indicated that they had received certificates as their highest levels of professional education or training in records or information management, whilst six $(13.3 \%)$ had received diplomas in records or information management.

In addition, 36 labour organisations (41.9\%) regarded seminars and workshops as the most useful for meeting the training needs in records management. Only seven $(8.1 \%)$ of the labour organisations regarded on-the-job training as useful (see Table 11).

Studies that the IRMT (2003:5) conducted in the ESARBICA region showed a lack of core competencies in managing records and archives. Nengomasha (2009:178) also cited the lack of training as one of the factors that led to poor recordkeeping in the public service in Namibia, where only

TABLE 10: Highest levels of education or training in records or information management $(N=45)$.

\begin{tabular}{lcc}
\hline Level of education & \multicolumn{2}{c}{ Frequency } \\
\cline { 2 - 3 } & Total & $\%$ \\
\hline Advanced diploma & - & - \\
Other & - & - \\
Diploma & 6 & 13.3 \\
None & 7 & 15.6 \\
Certificate & 10 & 22.2 \\
No response & 22 & 48.9 \\
\hline Total & $\mathbf{4 5}$ & $\mathbf{1 0 0}$ \\
\hline
\end{tabular}

TABLE 11: Most useful ways of meeting the training needs in records management $(N=45)$.

\begin{tabular}{lcc}
\hline Ways of meeting training needs & \multicolumn{2}{c}{ Frequency } \\
\cline { 2 - 3 } & Total & $\mathbf{\%}$ \\
\hline On-the-job training & 7 & 8.1 \\
Internships & 9 & 10.5 \\
Using consultants & 12 & 14 \\
Training in records schools & 22 & 25.6 \\
Seminars and workshops & 36 & 41.9 \\
\hline Total & $\mathbf{8 6}$ & $\mathbf{1 0 0}$ \\
\hline
\end{tabular}


two $(20 \%)$ of the ten heads of the recordkeeping functions reported that they had attended some records management training or awareness course.

On the other hand, according to Keakopa (2006:178), Botswana had done quite well in training a records management cadre although a challenge remained in terms of training in electronic records and generally inadequate staffing in the public sector. Moloi (2006:52) confirmed that, of 14 state departments, 13 (93\%) had a well-trained cadre in records management. Two (14.3\%) had master's degrees, two $(14.3 \%)$ had bachelor degrees and five $(35.7 \%)$ had diplomas. Only one (7.1\%) reported no training at all. This suggests that, unlike the labour organisations, the public sector in Botswana has benefited from the government's robust longterm human resource development strategy. However, more training in records management is still necessary, particularly for managing e-records.

\section{Managing vital records and disasters}

Vital records are those that labour organisations cannot operate without and which they need to sustain their operations during, or after, a disaster or calamity. Examples include legal and financial records. Therefore, managing vital records and disasters requires that organisations protect their records in order to maintain business continuity (ISO 15489-1 2001: Section 4.2.5.2).

Good records management practice means identifying vital records and information and then developing a records security policy. Managing vital records and disasters refers to mitigation and recovery because it relates to emergency preparedness. Usually contingency planning is essential. NARA (2011) lists as issues:

- determining the most critical activities that organisations must perform in a disaster

- identifying which records support those critical activities and the resumption of normal operations

- identifying which records series or electronic information systems contain information organisations need to protect their legal and financial rights, and the people that their actions affect directly, and preserving copies of these records

- establishing and implementing a plan to recover records (regardless of the medium of recording) that are damaged in an emergency or disaster.

The survey sought to determine whether labour organisations appreciated and valued the need to identify and manage their most valuable records, that is, those without which they could not function. The survey showed that most labour organisations were aware of the need for managing vital records and the implications of a disaster.

Table 12 summarises the labour organisations' admission that they need to protect their vital records in the event of disasters. Thirty (23.4\%) said they identified vital records, $24(18.8 \%)$ developed records protection measures, 22
(17.2\%) identified potential disasters, 20 (15.6\%) developed appropriate facilities for storing vital records, 18 (14.1\%) said they assigned responsibilities for this purpose whilst 14 $(11 \%)$ said that they conducted audit and test programmes in anticipation of disasters.

Of those that indicated the need for a vital records management programme and for disaster preparedness, 23 (18.1\%) of the respondents stated that the disasters that were likely to affect records in labour organisations were computer system failures, followed by unauthorised intrusions (22 organisations, or $17.3 \%$ ) and leaking roofs (see Table 13).

These results confirm the findings of other studies, like those of Kemoni (2007:320), who found that 40 (89.2\%) of the respondents in the Kenya public sector survey 'confessed that they neither had criteria for evaluating potential hazards nor disaster management plan'.

In Botswana, the Hlabaangani and Mnjama (2008:63) empirical study of disaster preparedness confirmed that information centres in Botswana were badly prepared for disasters, lacked disaster preparedness plans, had inadequate policies and procedures, staff that were ill-equipped for managing disasters and that there was an absence of conservation and restoration facilities.

With regard to identifying vital records, the study revealed that none of the information centres had identified and listed their vital information materials. Tshotlo and Mnjama (2010:29) confirmed that nine $(75 \%)$ of the respondents at the GCC in Botswana believed that the organisation did not have a disaster plan, although they emphasised securing 'confidential records...housed and managed by the secretary in the Town Clerk's office'. The town clerk is the chief

TABLE 12: Indication of the need for vital records programmes in labour organisations $(N=45)$.

\begin{tabular}{lcc}
\hline Needs & \multicolumn{2}{c}{ Frequency } \\
\cline { 2 - 3 } & Total & $\mathbf{\%}$ \\
\hline Audit and test programme procedures & 14 & 11.0 \\
Assign responsibilities & 18 & 14.1 \\
Develop appropriate facilities for storing vital records & 20 & 15.6 \\
Identify potential hazards & 22 & 17.2 \\
Develop measures to protect records & 24 & 18.8 \\
Identify vital records & 30 & 23.4 \\
\hline Total & $\mathbf{1 2 8}$ & $\mathbf{1 0 0}$ \\
\hline
\end{tabular}

TABLE 13: Disasters likely to affect records in labour organisations $(N=45)$.

\begin{tabular}{lcc}
\hline Disasters & \multicolumn{2}{c}{ Frequency } \\
\cline { 2 - 3 } & Total & \% \\
\hline Bomb threats & 3 & 2.4 \\
Explosions & 5 & 3.9 \\
Floods & 10 & 7.9 \\
Food and drink in storage area & 11 & 8.7 \\
Pest infestations & 17 & 13.4 \\
Leaking roofs & 18 & 14.2 \\
Sabotage & 18 & 14.2 \\
Unauthorised intrusions & 22 & 17.3 \\
Computer system failures & 23 & 18.1 \\
\hline Total & $\mathbf{1 2 7}$ & $\mathbf{1 0 0}$ \\
\hline
\end{tabular}


executive officer of the city council. In all, the study reported that there were no clear guidelines to deal with disasters.

The government of Botswana formulated a National Policy on Disaster Management that the Presidential Directive No. CAB 27/96 approved in 1996. In addition, the National Disaster Management Office (NDMO), a unit that falls under the Development Division in the Office of the President, was established (Hlabaangani \& Mnjama 2008:64) in 1998. The national policy for disaster management recognises that Botswana is prone to a number of disasters like drought, floods, severe weather (hail and lightning strikes), veld fires, epidemics, pest infestations, industrial accidents and chemical spills (Hlabaangani \& Mnjama 2008). However, the policy does not deal with disasters that affect individual organisations but with emergencies in communities. Therefore, the national policy encourages government and non-governmental organisations to develop their own internal disaster plans because of the dangers these disasters pose. Labour organisations will do well to embark on designing their own sectoral disaster plans.

\section{Managing mail}

Managing mail is a critical component of managing records in organisations. Operational and service effectiveness demands that organisations handle mail in timely and costeffective ways.

The researchers asked respondents, using a multi-response list, to state the key mail management functions that the labour organisations performed. The results showed that receiving mail had the highest score of $36(16.2 \%)$, then opening mail, with 29 responses (13.1\%) and delivering mail to action offices, with 26 responses $(11.7 \%)$. They were the leading activities that constituted the mail management programme in labour organisations. Respondents did not rate filing mail $(9.9 \%)$, sorting mail $(9.5 \%)$, classifying mail $(6.8 \%)$ and controlling mail movement (5.9\%) highly, yet they are key to managing mail effectively.

Most respondents indicated, in interviews, that they had received criticism for their delayed or perceived lack of response to official communications. Observations also showed that there were inconsistent application file reference numbers on outgoing correspondence, thereby undermining the maintenance of a complete record of correspondence.

Table 14 shows that, of the labour organisations that responded, $30(66.7 \%)$ did not use any tools for circulating mail. Only four $(8.9 \%)$ used file movement cards, whilst one $(2.2 \%)$ used systematic searches.

TABLE 14: Tools labour organisations use to control the movement of mail $(N=45)$.

\begin{tabular}{lcc}
\hline Tools & \multicolumn{2}{c}{ Frequency } \\
\cline { 2 - 3 } & Total & $\mathbf{\%}$ \\
\hline Systematic searches & 1 & 2.2 \\
File movement cards & 4 & 8.9 \\
Daily lists of wanted files & 5 & 11.1 \\
No tools for circulating mail & 30 & 66.7 \\
No response & 5 & 11.1 \\
\hline Total & $\mathbf{4 5}$ & $\mathbf{1 0 0}$ \\
\hline
\end{tabular}

There were no clear guidelines for the types of correspondence that organisations should track. This leads to delays in processing in-coming and out-going correspondence that the organisations receive.

Other studies in the public sector in the ESARBICA indicated that there were attempts to introduce some elaborate mail management programmes, although they mentioned some challenges in managing mail. For example, Kemoni (2007:295) reported that, in the Kenya public service, all had a mail management programme and that 129 (82.2\%) respondents cited receiving, sorting, opening, classifying, filing and delivering mail to action officers as their mail management activities.

In Botswana, Tshotlo and Mnjama (2010:26) indicated that there was a mail management programme at the GCC, although they mentioned that there were some delays in circulating mail. However, unlike public organisations, labour organisations did not report having a wellestablished mail management programme. This suggests that labour organisations need to re-examine all business processes for receiving, distributing, tracking and managing correspondence. They should attend specifically to redundant processes and bottlenecks. Labour organisations could also learn from other organisations that have modernised their systems and use technology to process, distribute and manage mail more efficiently.

\section{Managing emails}

Although most labour organisations reported they had, as per organisational policy, not adopted emails as official ways of communicating, $25(55.6 \%)$ of the organisations said that they used it 'very often' and $10(22.2 \%)$ said they used it 'often'. This yields a combined score of 35 (77.8\%). Furthermore, follow-up interviews revealed that labour organisations thought that they had some cases where the admissibility and authenticity of email communication had been questioned as evidence of transactions in executing their work. They believed that, whilst email may be as good a record as any other, many were still apprehensive about the authenticity of emails. Sixteen (35.6\%) respondents indicated that they used the Internet very often. However, only three $(6.7 \%)$ labour organisations indicated they used it at times or very often in their work. The rest were not at all sure (see Table 15).

Labour organisations also indicated that the challenges of authenticity and admissibility were key reasons that had led to the slow adoption of ICTs. This seems to suggest that email poses huge challenges for most labour organisations. One of the major reasons was that there were no policies or procedures about using and managing emails. For example, in most of the labour organisations, the users created and disposed of emails and attachments mainly at their own discretion without referring to institutional standards or controls. Some users said they 'archived' messages, whilst others printed and filed messages they thought were official and important. 
TABLE 15: Extent of use of ICTs in labour organisation functions $(N=45)$.

\begin{tabular}{|c|c|c|c|c|c|c|c|}
\hline Communication tool & Neverused & Rarely used & Used at times & Used often & Used very often & No response & Total \\
\hline Fax & $1(2.2 \%)$ & $4(8.9 \%)$ & $7(15.6 \%)$ & $8(17.8 \%)$ & $21(46.7 \%)$ & $4(8.9 \%)$ & $45(100 \%)$ \\
\hline Telephone & $1(2.2 \%)$ & $1(2.2 \%)$ & $2(4.4 \%)$ & $7(15.6 \%)$ & $31(68.9 \%)$ & $3(6.7 \%)$ & $45(100 \%)$ \\
\hline Cellphone & $2(4.4 \%)$ & $2(4.4 \%)$ & $1(2.2 \%)$ & $8(17.8 \%)$ & $29(64.4 \%)$ & $3(6.7 \%)$ & $45(100 \%)$ \\
\hline Internet & $8(17.8 \%)$ & - & $4(8.9 \%)$ & $7(15.6 \%)$ & $16(35.6 \%)$ & $10(22.2 \%)$ & $45(100 \%)$ \\
\hline Email & $4(8.9 \%)$ & - & $1(2.2 \%)$ & $10(22.7 \%)$ & $25(55.6 \%)$ & $5(11.1 \%)$ & $45(100 \%)$ \\
\hline Website & $17(37.8 \%)$ & $1(2.2 \%)$ & $3(6.7 \%)$ & $2(4.4 \%)$ & $3(6.7 \%)$ & $19(42.6 \%)$ & $45(100 \%)$ \\
\hline Web 2.0 (Facebook) & $19(42.2 \%)$ & $2(4.4 \%)$ & $1(2.2 \%)$ & $1(2.2 \%)$ & - & $22(48.9 \%)$ & $45(100 \%)$ \\
\hline Web 2.0 (YouTube) & $21(46.7 \%)$ & $1(2.2 \%)$ & - & - & - & $23(51.1 \%)$ & $45(100 \%)$ \\
\hline Web 2.0 (Twitter) & $21(46.7 \%)$ & - & - & $1(2.2 \%)$ & - & $23(51.1 \%)$ & $45(100 \%)$ \\
\hline
\end{tabular}

ICT, communication technology.

These challenges are not unique to labour organisations. In Botswana, several scholars have alluded to these challenges. Keakopa (2008:80) confirmed that most organisational policies tended to concentrate on regulating usage rather than managing the resulting records. Keakopa (2008:80) revealed that there were no clear policies for creating, using, storing, retaining or disposal of email in Botswana. Similar studies in Botswana, by Moloi (2006), Tshotlo and Mnjama (2010), Nengomasha (2009) in Namibia and Sejane (2005) in Lesotho, all refer to the absence of clear policies about managing emails. Tshotlo and Mnjama (2010) recently revealed that, at the GCC in Botswana:

basically, respondents use[d] computers for e-mail... typing of documents and sending of correspondence, but whatever information is sent or received via e-mail remain[ed] with individuals who [were] at [liberty] to delete or save the e-mail.. (p. 30)

\section{Managing e-records}

With regard to managing e-records, it was clear from the survey that most labour organisations were likely to conduct their operations and business using ICTs although they would continue to create, receive, maintain and use paper records in the foreseeable future. The current study concurs with the earlier study of the IRMT (2003:5). It showed that there were various barriers to managing e-records in developing countries. In fact, the most prevalent challenges labour organisations experienced with managing electronic records were that there were insufficient staff members with expertise in managing records $(24.5 \%)$, lack of relevant training $(21.7 \%)$ and low awareness of ICT issues (17\%). See Table 16.

TABLE 16: Challenges of managing electronic records in labour organisations $(N=45)$.

\begin{tabular}{|c|c|c|}
\hline \multirow[t]{2}{*}{ Challenges } & \multicolumn{2}{|c|}{ Frequency } \\
\hline & Total & $\%$ \\
\hline $\begin{array}{l}\text { Insufficient staff with expertise in managing } \\
\text { records }\end{array}$ & 26 & 24.5 \\
\hline $\begin{array}{l}\text { Inadequate funding to buy enough computers and } \\
\text { accessories }\end{array}$ & 21 & 19.8 \\
\hline Lack of relevant training & 23 & 21.7 \\
\hline $\begin{array}{l}\text { Poor communication between users and } \\
\text { information technology (IT) officers }\end{array}$ & 4 & 3.8 \\
\hline Security & 7 & 6.6 \\
\hline Technology obsolescence & 7 & 6.6 \\
\hline Low awareness of ICT issues & 18 & 17 \\
\hline Total & 106 & 100 \\
\hline
\end{tabular}

Studies in Botswana that Keakopa (2006), Moloi (2006), Tshotlo and Mnjama (2010) carried out in the public sector and local government confirm these findings. For example, Keakopa (2006:135-136) revealed that, in Botswana, there were challenges about managing paper and electronic systems, back-up procedures, the long-term preservation of electronic records, issues of access and coping with change from manual to computerised systems. Moloi (2006:105-107) also mentioned lack of procedures, the absence of policy and legislative frameworks as well as a lack of skills, amongst others, as challenges that the public sector faces.

Tshotlo and Mnjama (2010:30-32) conducted a records management audit in a local government and the GCC. They revealed several challenges, like the absence of records management policies to guide the creation, storage, access, retention and disposal of records.

\section{Recommendations and strategies}

Labour organisations in Botswana should consider the recommendations and strategies that follow to improve their records management practices.

\section{Legislative and policy framework}

The study found that the legislative framework was weak. Although there was some guidance about the requirements for records management in the relevant acts, instructions and instruments, there was no detailed guidance about the policies and practices that labour organisations need to manage records.

Therefore, for labour organisations to become aware of, and comply with, any legislative requirements that relate to records and information, they will need to develop and introduce a range of internal policies, standards and procedures to enable them to fulfil the statutory obligations and to improve their operational efficiency. They could use other countries, like the United Kingdom (UK), Australia, the United States of America (USA) and South Africa as models for benchmarking these policies. The models from these countries focus on responsibilities and obligations and specify monitoring and compliance mechanisms. The best of these models also recognise the interdependence between paper and digital records and the need to integrate and coordinate the management of records in all media. 


\section{Creating and capturing records}

From the survey, it is clear that most labour organisations lacked policies and procedures for creating records. There were no recognised procedures and standards for titling, indexing, classifying and describing records so that organisations could organise them systematically and retrieve them easily.

Therefore, the researchers recommend that labour organisations develop policies for creating records that stipulate the requirements for capturing, registering, classifying, retaining, storing, tracking, accessing records and disposing of them (ISO 15489-1 2001:7). Organisations need these policies, standards and procedures to manage records throughout their life cycles based on records continuum principles. For example, the mechanisms of best practice behind the records continuum model emphasises that, in an electronic environment, there is a need for:

identifying records of organisation activities that need to be retained, then implementing business systems designed with built-in recordkeeping capability [that] ensures capturing records of evidential quality as they are created. (Xiaomi 2003:27)

\section{Organising and classifying}

The researchers established that there were no well-defined classification schemes to guide the organisation of records in most labour organisations. Therefore, the researchers recommend policies, standards and procedures for organising, numbering and describing or indexing records. Developing a classification and filing system should use the functions the labour organisations perform as their basis (Shepherd \& Yeo 2003; ISO 25489 2001). Once in place, organisations should make the file classification systems available to all staff members to increase acceptance and ownership.

\section{Tracking and accessing files}

The researchers established that tracking files was problematic and this made access cumbersome. They recommend that labour organisations design and implement effective systems for tracking files and actions in paper-based and digital recordkeeping systems and ensure that they build adequate audit trails into all systems so that they can maintain a history of access to, and use of, records. Organisations can, and should, link the monitoring and use of records to track workflow and actions because they will increase efficiency. This is particularly effective for the electronic environment (ISO 15489-1 2001: Section 8.3.6).

\section{Appraisal, retention and disposal}

Labour organisations should examine all the legislation that affects the retention and disposal of records and determine their own business needs before continuing to retain all categories of available records. A comprehensive record survey of existing records should support this.

Labour organisations should develop comprehensive schedules for retaining and disposing of records that they keep up to date and implement as a matter of routine. They should determine their retention requirements for all the main categories of their records by assessing their value for supporting administrative, financial, legal, historical, research or information needs. Labour organisations should also develop efficient mechanisms for disposing of, or destroying, the records they no longer need, whether they are hard copy or digital. The processes should be secure, complete and carefully recorded.

Labour organisations should develop policies and standards to support the protection and security of records throughout their life cycles until they can safely destroy or delete them. These could include email policies, policies for using records outside offices, policies for managing the records of staff who leave the organisations and policies for applying retention rules for all electronic data and information.

\section{Storing and preserving records}

The survey revealed that storage and preservation records are weak. Labour organisations should establish functional record-keeping management units. This would also lead to the rationalisation of their storage requirements and improve the accessibility of semi-current records that are bundled together with current files on shelves. Implementing retention schedules could create a balance between creating and disposing of records (as the organisations create new records, so they destroy older ones that are no longer useful). This will save storage space and time that staff would otherwise spend looking for records.

The study also established that, in terms of preservation strategies and practices between paper-based and digital documents, most labour organisations faced similar problems. They include poor storage of electronic versions of documents or records, poor migration strategies to newer hardware and software technologies, poor control of access as well as using defective storage media.

The researchers recommend that labour organisations develop programmes for preserving digital materials. Detailed studies on needs and the reorganisation of analog systems for identifying, selecting and classifying materials for digitisation should precede them.

\section{Access and retrieval}

Introducing retention and disposal schedules could help labour organisations to control the destruction of records that are no longer useful. Labour organisations should also improve their retrieval procedures. Retention schedules would also ensure easy retrieval as there would be fewer current records to search. The retention schedules should apply to both paper and electronic records. Another possibility is to use intern students of record management from the University of Botswana during their winter break or on a part-time basis to assist with appraising and decongesting the records that are blocking their recordkeeping systems. 


\section{Managing vital records and disasters}

The study shows that there is no policy or programme for identifying, managing and protecting vital records in the event of a disaster in most labour organisations. Therefore, it is necessary to identify vital records and information and then develop policies for managing disasters that could work together with the ICT security policies for protecting records and information. Labour organisations should design and implement well-orchestrated disaster management plans and review them regularly.

\section{Managing mail}

The study also found that there was dissatisfaction with the current procedures for handling both incoming and outgoing mail in labour organisations, and which respondents said were very inefficient.

Labour organisations will need to re-examine all their business processes for receiving, distributing, tracking and managing correspondence or mail. They should pay specific attention to redundant processes and bottlenecks. They could learn from other organisations in the public and business sectors that have modernised their systems and use a variety of mail management technologies to make processing, distributing and managing mail more efficient.

\section{Staffing for, and training in, managing records}

The researchers recommend that labour organisations employ qualified personnel to run the record and information management functions. They could also work hand in hand with institutions like the University of Botswana (UB) to develop short-term winter programmes to improve their skills bases. Other organisations in the public sector, like BNARS, the Botswana National Library Services (BNLS) and NGOs like the Botswana Council of Non-Governmental Organisations (BOCONGO) have benefited from similar arrangements in the past.

In addition, labour organisations should have comprehensive programmes to orientate their staff members about the central role of records in their organisations and the need to manage them properly. They could achieve this through continuous refresher courses. Labour organisations should design programmes that sensitise staff to managing records and good recordkeeping practices and conduct them regularly. Training and awareness modules that incorporate trade union (business) knowledge and understanding could complement them.

\section{Managing e-records}

It is necessary to incorporate records management components into both electronic business and office systems so that they can capture records seamlessly and protect the integrity of records over time. Labour organisations need policies and procedures that allow them to manage paper and digital records as integrated wholes. The policies and procedures should also apply to managing emails.

\section{Conclusion}

This article has attempted to record the state of the current records management practices in labour organisations in Botswana. The findings show that, although some records management functions do exist, they fall below envisaged records management standards in all labour organisations. Problems include:

- creating and capturing records

- organising and classifying records

- access and security

- storing records

- appraising, retaining and disposing of records

- human resource capacity

- managing vital records and disasters

- managing mail, including integrating e-records.

The researchers recommend that labour organisations adopt and implement best records management practices in order to promote successful and effective records management. It would help them to achieve their goals.

\section{Acknowledgements}

The researchers thank two anonymous reviewers for their comments.

\section{Competing interests}

The authors declare that they have no financial or personal relationship(s) that may have inappropriately influenced them when they wrote this paper.

\section{Authors' contributions}

The authors conceptualised the study together. T.K. (University of Botswana) designed the study and collected some of the data that the study reports as part of his doctoral studies. P.N. (University of South Africa) converted the study into a publishable journal article and dealt with the comments of the reviewers and the editors.

\section{References}

Akotia, P., 2002, Financial records management project: Phase three, paper submitted to the Government of Uganda, DFID Kampala, 17-28 January.

Bearman, D., 1994, Electronic evidence strategies for managing records in contemporary Organisations, Archives and Museums Informatics, Pittsburgh.

Friedrich Ebert Stiftung (FES), 2008, Trade unions in Botswana, FES, Gaborone. Handy, C.B., 1993, Understanding organisations, 4th edn., Penguin, London.

Hlabaangani, K. \& Mnjama, N., 2008, 'Disaster preparedness in information centres in Gaborone, Botswana', African Journal of Library, Archives and Information Science 18(1), 630-74

Hofstede, G., 1980, 'Culture's consequences, international differences in work-related values', Sage Publications, Beverly Hills.

International Records Management Trust (IRMT), 2003, Evidence-based government in the electronic age: case summaries, viewed 20 May 2008, from http://ww.irmt. org/evidence/index.html

International Records Management Trust (IRMT), 2008, Integrating records management in ICT system: good practice indicator, IRMT, London.

International Organisation for Standardisation (ISO), 2001, ISO 15489-1 Information and documentation-records management-part 1 general. ISO, Geneva.

Kalusopa, T., 2011, 'Developing an e-records readiness framework for labour organisations in Botswana', PhD Thesis, University of South Africa, Pretoria.

Kalusopa, T., 2010, 'E-records readiness - can we build a contextual and conceptual framework for labour organisation in Botswana?' ESARBICA Journal 29, 124-146. 
Kalusopa, T., 2009, 'Challenges of information and knowledge management in trade union in Botswana within the context of millennium development goals', Journal of African Studies and Development 1(1), 1-7. http://dx.doi. goals', Journal of African Studies
org/10.1108/01604950910971125

Kalusopa, T. \& Zulu, S., 2009, 'Digital heritage material preservation in Botswana: problems and prospects', Collection Building 28(3), 98-107.

Kanyenze, G., Kondo, K. \& Martens, J., 2006, The search for sustainable human development in Southern Africa, ANSA, Harare.

Katuu, S., 2004, Report on an investigation of electronic records in the Commonwealth, Unpublished manuscript, Johannesburg.

Keakopa, S., 2006, 'Management of electronic records in Botswana, Namibia and South Africa: Opportunities and Challenges', unpublished PhD Thesis, University College, London.

Keakopa, S.M, 2008, 'Management of electronic mail: a challenge for archivist and records managers in Botswana, Namibia and South Africa', ESARBICA Journal 27, 73-83.

Keakopa, S.M., 2010, 'Overview of archival and records management developments in the ESARBICA region', The Journal of the Australian Society of Archivists 38(1), 51-77.

Kemoni, H.N., 2007, 'Records management practices and public service delivery in Kenya', PhD Thesis, University of KwaZulu-Natal, Pietermaritzburg, South Africa.

Moloi, J., 2006, 'An investigation of e-records management in government: case study of Botswana', unpublished MA Thesis, University of Botswana.

Mutiti, N., 2001, 'The challenges of managing electronic records in the ESARBICA region', ESARBICA Journal, 20(3), 57-61

Mutula, S.M. \& Brakel, P., 2006, 'E-readiness of SMEs in the ICT sector in Botswana with respect to information access', The Electronic Library, 24(3), 402-417. http:// dx.doi.org/10.1108/02640470610671240

Mutula, S.M. \& Wamukoya, J., 2007, 'E-government readiness in east and southern Africa', Encyclopedia of Digital Government 2, 571-579.

National Archives and Records Administration (NARA), 2011, Vital Records And Records Disaster Mitigation And Recovery: An Instructions Guide, viewed 20 May 2011, from http://www.archives.gov/recordsrecordsmanagement/policyand guidance/prod3rev.htm

Nengomasha, 2009, 'A study of electronic records management in the Namibian public service in the context of e-government', PhD thesis, University of Namibia.

Ngulube, P., 2004, 'Implications of technological advances for access to the cultura heritage of selected countries in sub-Saharan Africa', Government Information Quarterly 21, 143-155. http://dx.doi.org/10.1016/j.giq.2004.01.003
Ngulube, P. \& Tafor, V., 2006, 'An overview of the management of public records and archives in the member countries of the East and Southern Africa regional branch of the international council on archives (ESARBICA)', Journal of the Society of

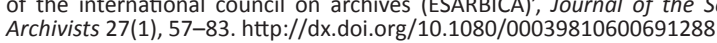

Northern Territory National Archives Services, 2006, Guidelines for Conducting a Records Survey, viewed 05 May 2011, from http://www.nt.gov/nreta/nta/ records/pdf/conducting_survey.pdf

Rainsberger, P.K., 1998, Collective bargaining historical models of collective bargaining in the U.S. Steward Notes 1(2)

Ramokate, K. \& Moatlhodi, T., 2010, 'Battling the appraisal backlog: a challenging professional obligation for Botswana National Archives and Records Services' ESARBICA Journal 29, 67-86.

Registrar of Trade Unions, 2011, Trade union registration statistics, Office of the Registrar of Trade Unions, Gaborone

Reed, B., 1997, 'Electronic records management in Australia', Records Management Journal 7(3), 1-13.

Reed, B., 2005, 'Records' in S. McKemmish, M. Piggott, B. Reed \& F. Upward (eds.), Archives: recordkeeping in society, pp. 101-130, Centre for Information Studies, Wagg, NSW. http://dx.doi.org/10.1108/eb027111

Sejane, L., 2005, 'An investigation into the management of electronic records in the public service in Lesotho', MA thesis, University of KwaZulu-Natal.

Shepherd, E. \& Yeo, G., 2003, Managing records: a handbook for principles and practices, Facet Publishing, London.

Tafor, V.F., 2003, 'Digital technology-understanding the problems posed by information technology in generating and managing records from a Third World perspective', ESARBICA Journal 22(1), 72-76.

Tshotlo, K. \& Mnjama, N., 2010, 'Records management audit: the case of Gaborone City Council', ESARBICA Journal 29, 5-35.

Wamukoya, J. \& Mutula, S., 2005, 'Capacity-building requirements for e-records management: the case in east and Southern Africa', Record Management Journal 15(2), 71-79. http://dx.doi.org/10.1108/09565690510614210

Wamukoya, J. \& Mnjama, N., 2007, 'E-government and records management: an assessment tool for e-records readiness in government', The Electronic Library 25(3), 274-284. http://dx.doi.org/10.1108/02640470710754797

Wato, R., 2006, 'E-records readiness in the ESARBICA Region: challenges and the way forward', ESARBICA Journal 25, 69-83.

World Bank, 2006, Why records management? Records management as a key support for development effectiveness, viewed 20 January 2008, from http://web. worldbank.org/WBSITE/ EXTERNAL/EXTABOUTUS/EXTARCHIVES/

Xiaomi, A., 2003, 'An integrated approach to records management', Information Management Journal, July/August, 24-30. 